GABA, and alkaloids in cell and root cultures of Solanaceae. In: Primary and Secondary Metabolism of Plant Cell Cultures. (ed. K. H. Newmann, W. Barz, and E. Reinhard) pp 174-186, Springer-Verlag, Heidelberg.

15 Rice, E. L. (1983). Pest Control with Nature's Chemicals: Allelochemics and Pheromones in Gardening and Agriculture. 224 pp. University of Oklahoma Press, Norman.

16 Cosico, E. G., Norton, R. A., Towers, E., Finlayson, A. J., Rodriguez, E. AND Towers, G. H. N. (1986). Production of antibiotic thiarubrines by a crown gall tumor line of Chaenactis douglasii. J. Plant Physiol. 124, 155-164. 17 Flores, H. E., Pickard, J. J. and Hoy, M. W. (1988). Production of polyacetylenes and thiophenes in heterotrophic and photosynthetic root cultures of Asteraceae. In: Chemistry and Biology of Naturally-Occurring Acetylenes and Related Compounds (NOARC), (ed. J. Lam, H. Breteler, T. Arnason and L. Hansen) pp. 233-254, Elsevier, Amsterdam.

18 Parodi, F. J., Fischer, N. H. and Flores, H. E. (1988). Benzofuran and bithiophenes from root cultures of Tagetes patula. J. Nat Prod. 51, 594-595.

19 Mugnier, J. (1988). Establishment of new axenic hairy root lines by inoculation with Agrobacterium rhizogenes. Plant Cell Repts., 7, 9-12.

20 Үамамото, H. (1988). Paeonia spp.: in vitro culture and the production of paeoniflorin. In: Biotechnology in Agriculture and Forestry 4, (ed. Y. P. S. Bajaj) pp. 464-483. Springer-Verlag, Heidelberg.

21 Yamada, Y. and Hashimoto, T. (1988). Biosynthesis of tropane alkaloids. In: Applications of Plant Cell and Tissue Culture, (ed. G. Bock and J. Marsh) pp. 199-212, CIBA Foundation Symp. 137, John Wiley and Sons, Chichester. 22 Ersek, T. and Kiraly, Z. (1986). Phytoalexins: warding off compounds in plants? Physiol. Plantarum 86, 343-346.

23 Signs, M. W. and Flores, H. E. (1989). Elicitation of sesquiterpene phytoalexin biosynthesis in transformed root cultures of Hyoscyamus muticus L. Plant Phys. 89(S), 135.

24 Sato, N., Yoshizawa, Y., Mryazaki, H., and Murai, A. (1985). Antifungal activity to Phytophthora infestans and toxicity to tuber tissue of several potato phytoalexins. Ann. Phytopath. Soc. Japan. 51, 494-497.

25 Flores, H. E. (1987). Use of plant cells and organ culture in the production of biological chemicals. In: Biotechnology in Agricultural Chemistry, (ed. H. M. LeBaron, R. O. Mumma, R. C. Honeycutt, J. H. Duesing, J. F. Phillips and M. J. Haas) ACS Symp. Series 334, Washington D. C.

26 Aird, E. L. H., HAMill, J. D., Robins, R. J., and Rhodes, M. J. C. (1988). Chromosome stability in transformed hairy root cultures and the properties of variant lines of Nicotiana rustica hairy roots. In: Manipulating Secondary Metabolism in Culture. (ed. R. J. Robins \& M. J. C. Rhodes) pp. 137-144. Cambridge University Press, Cambridge.

27 Rhodes, M. J. C., Hamill, J., Parr, A. J., Robins, R. J. and Walton, N.
J. (1988). Strain improvement by screening and selection techniques. In: Manipulating Secondary Metabolism in Culture. (ed. R. J. Robins \& M. J. C. Rhodes) pp. 83-93. Cambridge University Press, Cambridge.

28 Harley, J. L. ANd Smith, S. E. (1983). Mycorrhizal Symbiosis. 483 pp. Academic Press, Inc., London.

29 Morandi, D., Bailey, J. A. And Gianinazzi-Pearson, V. (1984). Isoflavonoid accumulation in soybean roots infected with vesicular-arbuscular mycorrhizal fungi. Physiol. Plant Path. 24, 357-364.

30 Mugnier, J. AND Mosse, B. (1987). Vesicular-arbuscular mycorrhizal infection in transformed root-inducing T-DNA roots grown axenically. Phytopath. 77, 1045-1050.

31 BÉCARD, G. AND Fortin, J. A. (1988). Early events of vesicular-arbuscular mycorrhiza formation on Ri T-DNA transformed roots. New Phytol. 108 211-218

32 Hilton, M. G., Wilson, P. D. G., Robins, R. J., and Rhodes, M. J. C. (1988). Transformed root cultures - fermentation aspects. In: Manipulating Secondary Metabolism in Culture. (ed. R. J. Robins \& M. J. C. Rhodes) pp. 239-245. Cambridge University Press, Cambridge.

33 Taya, M., Yoyama, A., Kondo, O., Kobayashi, T. and Matsui, C. (1989). Growth characteristics of plant hairy roots and their cultures in bioreactors. $J$. Chem. Engin. Japan 22, 84-89.

34 Payne, G. F., Shuler, M. L. And Brodelius, P. (1987). Large scale plant cell culture. In: Large Scale Cell Culture Technology, (ed. B. K. Lydersen) pp. 193-229. Hanser Publishers, Munich.

35 Hamill, J. D., Parr, A. J., Rhodes, M. J. C., Robins, R. J. and Walton, N. J. (1987). New routes to plant secondary products. Biotechnology 5, $800-804$.

Mark W. Signs is a graduate student in the Plant Physiology Program; Hector E. Flores is Associate Professor of Plant Pathology at the Pennsylvania State University.

Please address reprints requests and correspondence to: Dr. H. E. Flores, 315 Wartik Bldg., Biotechnology Institute, The Pennsylvania State University, University Park, PA 16802. (U.S.A.). 


\section{Functional and Dynamic Aspects of the Mammalian Nucleolus}

\section{Uirich Scheer and Ricardo Benavente}

\section{Summary}

Nucleoli are the sites of ribosome biogenesis. Transcription of the ribosomal RNA genes as well as processing and initial packaging of their transcripts with ribosomal and non-ribosomal proteins all occur within the nucleolus in an ordered manner and under defined topological conditions. Components of the nucleolus have been localized by immunocytochemistry and their functional aspects investigated by microinjection of antibodies directed against the enzyme responsible for rDNA transcription, RNA polymerase I. The role of nascent transcripts in postmitotic formation of nucleoli will be discussed.

\section{Introduction}

Nucleoli are the most obvious structural elements of eukaryotic interphase cell nuclei. At the light microscopic level they appear as solitary or multiple spherical bodies which occupy - particularly in actively growing cells - a substantial portion of the total nuclear space (Fig. 1). Each nucleolus contains a cluster of transcriptionally active ribosomal RNA (rRNA) genes immersed in a 'cloud' of ribosomal precursor particles of various stages of maturation. Thus, a nucleolus represents a ribosome producing apparatus where synthesis and processing of the rRNA precursor molecules (pre-rRNAs) takes place as well as their coordinate assembly with specific ribosomal and nonribosomal proteins to form preribosomal particles. ${ }^{(1,2)}$ Hence, investigations of the functional organization of nucleoli

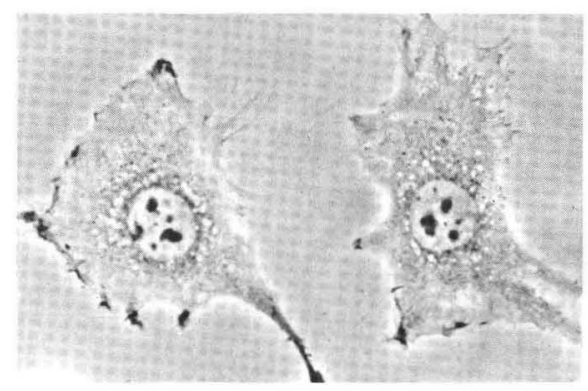

Fig. 1. Mouse fibroblasts (strain $\mathrm{L}-\mathrm{M}, \mathrm{TK}^{-}$) grown in culture (phase contrast microscopy). Note the prominent nucleoli. provide the fascinating possibility of correlating specific steps of the ribosome biosynthetic pathway with defined structures and the potential to gain more insight into the forces that maintain the highly ordered arrangement of specific genes with their products.

Nucleoli are highly dynamic structures as illustrated by their cyclical disappearance and reappearance during mitosis (except in cells of lower organisms with a 'closed' mitosis characterized by the persistence of the nuclear envelope). As already established in the early thirties by E. Heitz and B. McClintock, the nucleolus reforms at the end of mitosis at specific chromosomal sites termed 'nucleolus organizing regions' (NORs), which contain the tandemly reiterated rRNA genes. ${ }^{(1,3,4)}$ The process of nucleologenesis is particularly interesting as it involves a site-specific assembly of preformed nucleolar entities around the NORs.

\section{The Three Major Components of the Nucleolus}

Size, shape and ultrastructural aspects of nucleoli vary markedly depending on the cell type studied (e.g., compact vs. reticulated nucleoli) and the metabolic state of the cell (e.g., growing vs. resting cells). In spite of this variability, three morphologically distinct nucleolar components are usually recognized by thin section electron microscopy (Fig. 2a). The main body of the nucleolus of metabolically active cells is made up of particles $15-20 \mathrm{~nm}$ in diameter and hence termed granular component. Embedded in this granular mass are one or several islets of rounded structures of relatively low contrast, the fibrillar centers. These are invariably surrounded, either wholly or in part, by a layer consisting of tightly packed and densely staining fibrils, the dense fibrillar component $(D F C) .{ }^{(4)}$

Based on morphological similarities and the presence of argyrophilic proteins it is generally assumed that the fibrillar centers represent the interphase counterpart of the chromosomal NORs. ${ }^{(4)}$ However, the number of fibrillar centers in a given cell may change as a function of nucleolar activity and can exceed considerably the number of chromosomal NORs. ${ }^{(5)}$

Preferential chromatin staining reveals that nucleoli are enveloped by a more or less continuous layer of condensed chromatin which, at several places, penetrates deeply into the nucleolar body (Fig. 2b). These invaginations appear in ultrathin sections as isolated patches of intranucleolar condensed chromatin (Fig. 2b). Their striking association with the periphery of the fibrillar centers suggests that the transition from condensed, i.e. transcriptionally inactive DNA to the extended DNA of the fibrillar centers takes place here. ${ }^{(4)}$

\section{The Heart of the Nucleolus: The Active rRNA Genes}

Up to now it has not been possible to identify, by purely morphological criteria, the rRNA genes in nucleoli of 


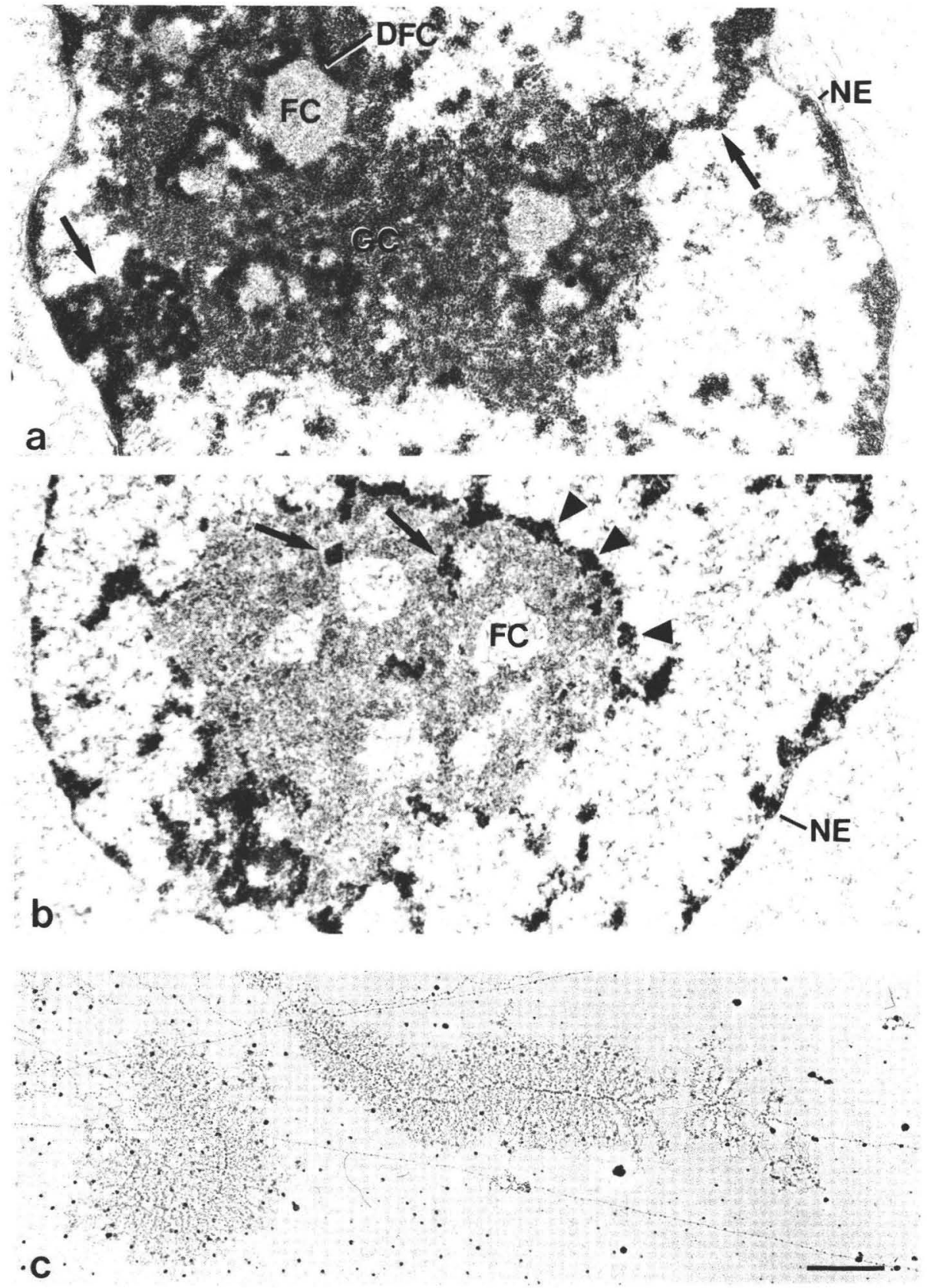

Fig. 2. Electron micrographs of nucleoli fixed in situ $(\mathrm{a}, \mathrm{b})$ and spread nucleolar chromatin (c) from mouse $\mathrm{LTK}^{-}$cells. Conventional sections (a) reveal the presence of the three major nucleolar components, i.e. the granular component (GC), the fibrillar centers (FC) and the surrounding dense fibrillar component (DFC). The nucleolus is connected by chromatin 'pedicles' (arrows in a) to the peripheral heterochromatin layer lining the nuclear envelope (NE). Preferential staining of DNA after formaldehyde fixation and embedding in LR White (b) clearly reveals the nucleolusassociated heterochromatin (arrowheads) and clumps of intranucleolar chromatin, often at the periphery of the fibrillar centers (arrows). A transcriptionally active mouse rRNA gene with an axial length of ca. $4 \mu \mathrm{m}$ is shown in c. Bar indicates $0.5 \mu \mathrm{m}$. The three micrographs are magnified to the same scale. cells fixed in situ (Fig. 2a). Visualization of transcriptionally active rRNA genes requires a method which destroys nucleolar integrity and releases the rRNA genes from topological constraints. The chromatin spreading technique originally developed by $\mathrm{O}$. Miller and associates has contributed substantially to the present understanding of rRNA gene organization, arrangement and chromatin structure. ${ }^{(6,7)}$ The rRNA genes of higher eukaryotes occur in multiple copies and are organized as tandem repeats, separated from each other by nontranscribed DNA segments or 'spacers'. (1) Transcription is mediated by the class I RNA polymerase $^{(8)}$ in concert with trans-acting protein factors involved in the initiation and termination reactions. ${ }^{(9)}$
Primary RNA transcripts contain the $18,5.8$, and $28 \mathrm{~S}$ rRNA sequences which become integrated into the ribosomes, in addition to sequences that are eliminated in the nucleolus by a series of processing steps. ${ }^{(1)}$ The entirety of the one or a few hundred copies of rRNA genes may be found at the NORs of only one chromosome pair (e.g. in Xenopus laevis) or can be subdivided into (probably unequal) portions according to the number of NOR-bearing chromosomes (e.g., 5 chromosome pairs in man and 3 in the mouse ${ }^{(3)}$ ).

Transcriptionally active rRNA genes from cultured mouse fibroblasts (Fig. 2c) reveal several morphological features common to this gene class. These are: 1) the dense packing of the chromatin axis with transcripts, 
indicative of a very high transcriptional activity, 2) the gradual increment in length of the lateral fibrils containing the nascent pre-rRNA chains in the direction of transcription, and 3 ) the terminal thickening of the free ends of the transcript fibrils. ${ }^{(6,7)}$ It is interesting to note that a single mouse rRNA transcription unit as spread for electron microscopy has about the same length (approximately $4 \mu \mathrm{m}$ ) as the diameter of a nucleolus in situ (Fig. 2; all micrographs are magnified to the same scale). In fact, the length of a single rDNA repeat unit (gene plus spacer $44 \mathrm{~kb}^{(1)}$ or $14.6 \mu \mathrm{m}$ of DNA) would be more than sufficient to span the whole nucleus.

It is obvious that in the living cell active rRNA genes must be considerably foreshortened and compacted. But where are they located within the nucleolar body?

\section{Intranucleolar Localization of the Active rRNA Genes}

A number of different experimental strategies have been adopted to trace the rRNA genes within the nucleolar body. As described below, the results of these studies are to some extent controversial and hence the important question of where nucleolar transcription takes place is still being discussed ${ }^{(10)}$. However, there is a general consensus that ribosome biogenesis is a vectorial process which begins within the confines of the fibrillar components and continues into the surrounding granular component of the nucleolus.

A large number of cytochemical studies have established the presence of DNA within the fibrillar centers $^{(4)}$ and in situ hybridization at the light and electron microscopic level has identified the ribosomal nature of this DNA. ${ }^{(11,12)}$ By contrast, rDNA was not detected in the surrounding DFC by this method. ${ }^{(12)}$ Essentially identical results were obtained by high resolution immunogold electron microscopy using a monoclonal antibody against DNA (Fig. 3a). ${ }^{(13,14)}$

Do the fibrillar centers contain transcriptionally active rDNA? In order to answer this question we took an approach based on the immunodetection of RNA polymerase I molecules which are dedicated to the transcription of the rRNA genes. ${ }^{(15)}$ Active rRNA genes are densely covered by transcribing RNA polymerase I molecules (Fig. 2c). Hence the distribution of this enzyme should accurately reflect the sites where the rRNA transcription units are located. As shown by immunogold electron microscopy, antibodies to RNA polymerase I decorate exclusively the fibrillar centers of nucleoli (Figs. 3b,c). ${ }^{(15-17)}$ A similar pattern of nucleolar distribution is also found for topoisomerase I, an enzyme required for proper transcription of the rRNA genes (Fig. 3d). ${ }^{(18)}$

Earlier electron microscopic autoradiographic studies of cells pulse-labelled with tritiated uridine have shown that the first nucleolar structure to be clearly marked by silver grains is the DFC. ${ }^{(4)}$ Although this is usually interpreted to mean that transcription of the
rRNA genes takes place in this component it is possible that this labelling results from other RNA species such as $5 \mathrm{~S} \mathrm{rRNA}^{(19)}$ or small nucleolar snRNAs ${ }^{(20)}$ synthesized at extranucleolar sites and rapidly transported to the nucleolus. Furthermore, it has to be kept in mind that radioactivity is incorporated at all stages of transcription and labelled transcripts include those which terminated during the labelling period, even after extremely short pulses. Consequently, the autoradiographic data are also compatible with the view that terminated transcripts become immediately translocated from their site of transcription to the DFC where they accumulate to high local concentrations, thereby facilitating their detection. Support for this notion comes from recent electron microscopic in situ hybridization showing that rRNA molecules occur at a relatively high density in the DFC but can also be detected in the fibrillar centers. ${ }^{(12)}$

Taken together, the prevailing current evidence points to the fibrillar centers as the site of rDNA transcription. The frequently observed location of the rRNA genes at the periphery of the fibrillar centers may facilitate the rapid and efficient transfer of the primary transcripts to the surrounding DFC once they are released from the rDNA template. In this respect both nucleolar components might be considered as a functional unit whose structural integrity is essential for the transition of the primary transcripts from the templatebound to the released state.

\section{Fibrillar Centers and the Dense Fibrillar Component: A Functional Unit}

Upon incubation of cultured cells with the adenosine analogue DRB (5,6-dichloro-1- $\beta$-D-ribofuranosylbenzimidazole), nucleoli reversibly disperse, lose their granular component and unravel into extended beaded strands which spread throughout the nuclear interior. ${ }^{(21)}$ Transcription of the rRNA genes continues relatively unabated under these conditions and immunofluorescence microscopy employing antibodies to RNA polymerase I reveals linear arrays of strongly fluorescent nuclear entities (Fig. 4a). Each polymerase I-positive dot probably represents a single rRNA transcription unit and the beaded strands linear arrays of tandemly repeated rRNA genes. ${ }^{(21)}$ Although these data indicate that rRNA synthesis is independent of the conventional nucleolar organization, electron microscopy of such DRB-treated cells demonstrates that the structural remnants are composed of two elements each, a fibrillar center and a closely apposed crescentshaped DFC (Fig. 4b). Thus, although the global architecture of the nucleoli is drastically changed in response to the drug, the specific association of both fibrillar components is maintained. Therefore we asked next whether or not this structural association is dependent on ongoing rDNA transcription. 

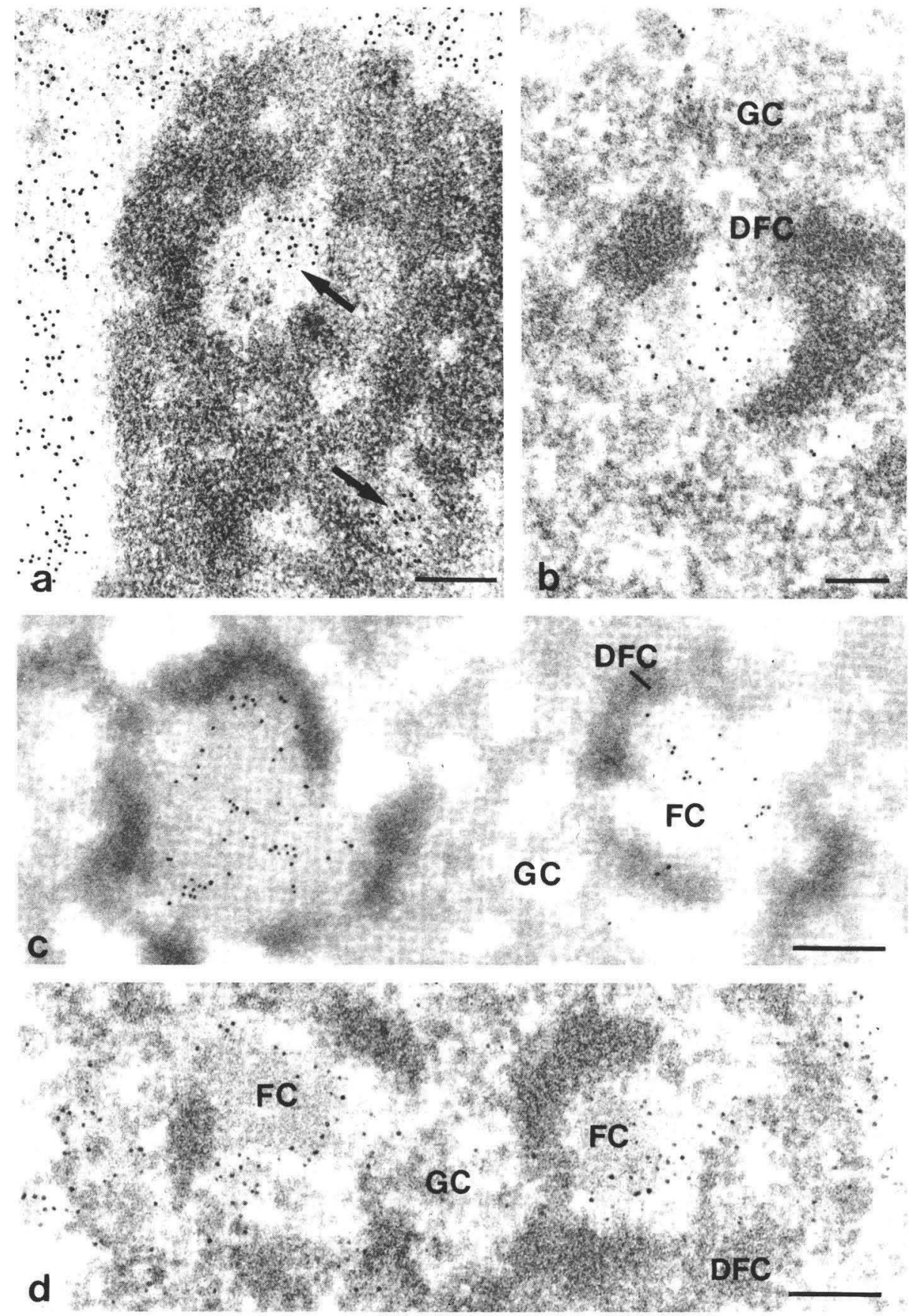

Fig. 3. Electron microscopic immunolocalization of DNA (a), RNA polymerase I $(b, c)$ and DNA topoisomerase I (d) using pre-embedding $(b, d)$ or postembedding $(\mathrm{a}, \mathrm{c})$ protocols and goldcoupled secondary antibodies. Rat liver was fixed with $3 \%$ formaldehyde, embedded in Lowicryl and ultrathin sections incubated with antibodies to DNA (a). ${ }^{(13,14)}$ Perinucleolar chromatin is labelled as well as the fibrillar centers (arrows in a). Cryosections ( $5 \mu \mathrm{m}$ ) of rat liver were treated with antibodies to RNA polymerase I (b) ${ }^{(15)}$ or DNA topoisomerase I (d) ${ }^{(18)}$ and processed for electron microscopy. ${ }^{(15)}$ In both cases the fibrillar centers are labelled by gold particles. In addition, anti-topoisomerase I also labels the extranucleolar chromatin. ${ }^{(18)}$ Ultrathin frozen sections of HeLa cells were incubated with anti-RNA polymerase I (c). ${ }^{(17)}$ Note the highly selective labelling of the fibrillar centers (c; courtesy of Dr. I. Raska ${ }^{(17)}$ ). Bars indicate $0.1(\mathrm{~b}, \mathrm{~d})$ and $0.2 \mu \mathrm{m}(\mathrm{a}, \mathrm{c})$.

\section{Selective Inhibition of rDNA Transcription by Microinjection of Antibodies to RNA Polymerase I}

A large number of chemicals are known to interfere with transcription of the rRNA genes and to induce extensive alterations of nucleolar structure. ${ }^{(1)}$ However, a correlation of the structural changes of the nucleoli with the molecular mechanisms of drug action is often difficult to establish since inhibitory effects usually extend also to non-ribosomal genes as well as to various cellular metabolic pathways.

In contrast, transcription of the rRNA genes is selectively blocked upon introduction of antibodies to
RNA polymerase I into cell nuclei. ${ }^{(22)}$ We therefore have microinjected polymerase I-antibodies into nuclei of cultured mammalian cells and studied nucleolar alterations by double-label immunofluorescence and electron microscopy. ${ }^{(23)}$ In order to follow the fate of the DFC we have used antibodies against fibrillarin, a protein specifically located in this nucleolar component. $(16,24,25)$

The effects are striking (Fig. 5). Shortly after antibody injection the DFC starts to disintegrate and to abandon the nucleolus until the whole nucleoplasm is filled with numerous extranucleolar bodies that, by 

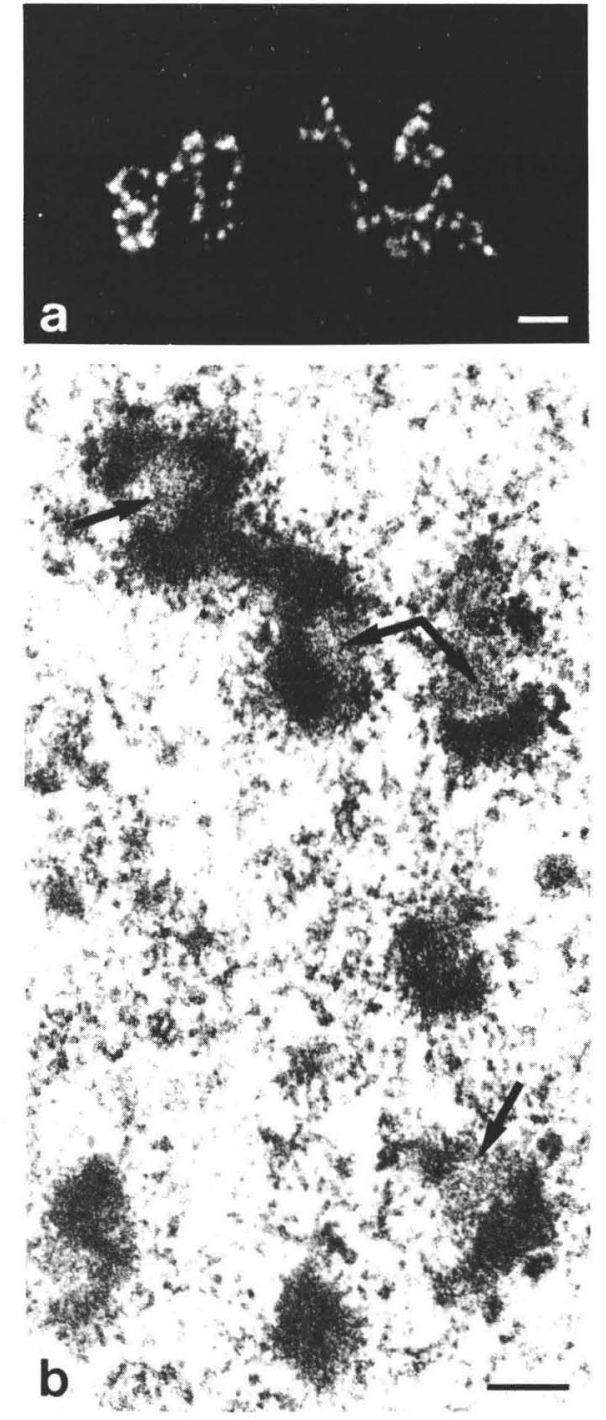

Fig. 4. Nucleolar unravelling induced by the drug $\mathrm{DRB}^{(21)}$ as seen by immunofluorescence microscopy with antibodies to RNA polymerase I (a) and electron microscopy (b). Structural remnants of the nucleolus are composed of a fibrillar center (arrows in b) and a surrounding dense fibrillar component. Bars indicate 2 (a) and 0.2 (b) $\mu \mathrm{m}$.

antibody staining, contain fibrillarin (Fig. 5c) but not polymerase I-molecules or a ribosomal marker protein for the granular component. ${ }^{(23)}$ These extranucleolar fragments appear in the electron microscope as aggregates composed of tightly packed fibrillar material (Fig. 5d). The residual nucleolus lacks the DFC and is mainly composed of granular material with one or two fibrillar centers embedded (Fig. 5d).

Thus, the nucleolar location and integration of the DFC into the nucleolus is critically dependent on ongoing transcription of the rRNA genes. Furthermore, the fragmentation into discrete extranucleolar entities upon cessation of pre-rRNA synthesis shows that the DFC represents a structure sui generis, inde- pendent of the transcriptional apparatus. Thus, it cannot be considered as a transient structure formed by the superposition of àctive rRNA genes and their early products.

\section{Inhibition of Nucleologenesis by Antibodies to RNA Polymerase I}

It is well established that nucleolar reformation at telophase begins with the aggregation of nucleolar material into discrete structural entities, termed prenucleolar bodies (PNBs), which subsequently amalgamate around the NORs into the developing nucleolar body. ${ }^{(26)}$ The PNBs contain fibrillarin ${ }^{(24,25,27,28)}$ as well as some other nucleolar proteins such as NO38/B23 and nucleolin/C23 $3^{(27,29)}$ but lack RNA polymerase I and topoisomerase I. Likewise, rDNA is also absent as shown by in situ hybridization. ${ }^{(27)}$ To find out whether the NOR-specific assembly of the PNBs requires rDNA transcription we have microinjected antibodies to RNA polymerase I into mitotic cells (Fig. 6). ${ }^{(28)}$ The injected cells complete division and the resulting daughters enter the $\mathrm{G}_{1}$-phase at a normal time scale. However, they do not reform nucleoli and their nuclei are filled with numerous PNBs as revealed by immunofluorescence microscopy with antibodies to fibrillarin (Fig. 6c) and electron microscopy (Fig. 6d).

These observations provide clear evidence that an active form of the RNA polymerase $I$ is required for the coalescence of preformed PNBs around the chromosomal nucleolar organizer regions. ${ }^{(26,28)}$ Suppression of rDNA transcription apparently 'freezes' early steps of nucleolar reconstitution at the normally transient PNBstage.

\section{Micronucleated Cells: Nuclei Lacking NORs}

Further support for the notion that the association between preformed DFC material and the NOR requires the activity of the rRNA genes comes from studies on micronucleated cells. Prolonged exposure of cultured cells to colchicine produces multinucleated cells in which the genome is subdivided into numerous small nuclei, each one containing a chromosomal subset or even a single chromosome. ${ }^{(30)}$ Those nuclei lacking an NOR are unable to organize nucleoli but instead produce numerous PNBs which react with antibodies specific for components of the DFC such as fibrillarin. ${ }^{(31)}$

\section{Interaction Between Nascent Transcripts and Fibrillarin}

Maintenance of the structural integrity of interphase nucleoli as well as generation of nucleolar structures following mitosis requires the activity of the rRNA genes. In order to gain more insight into the molecular processes involved, we have studied the interaction of fibrillarin with rRNA transcription units spread for 

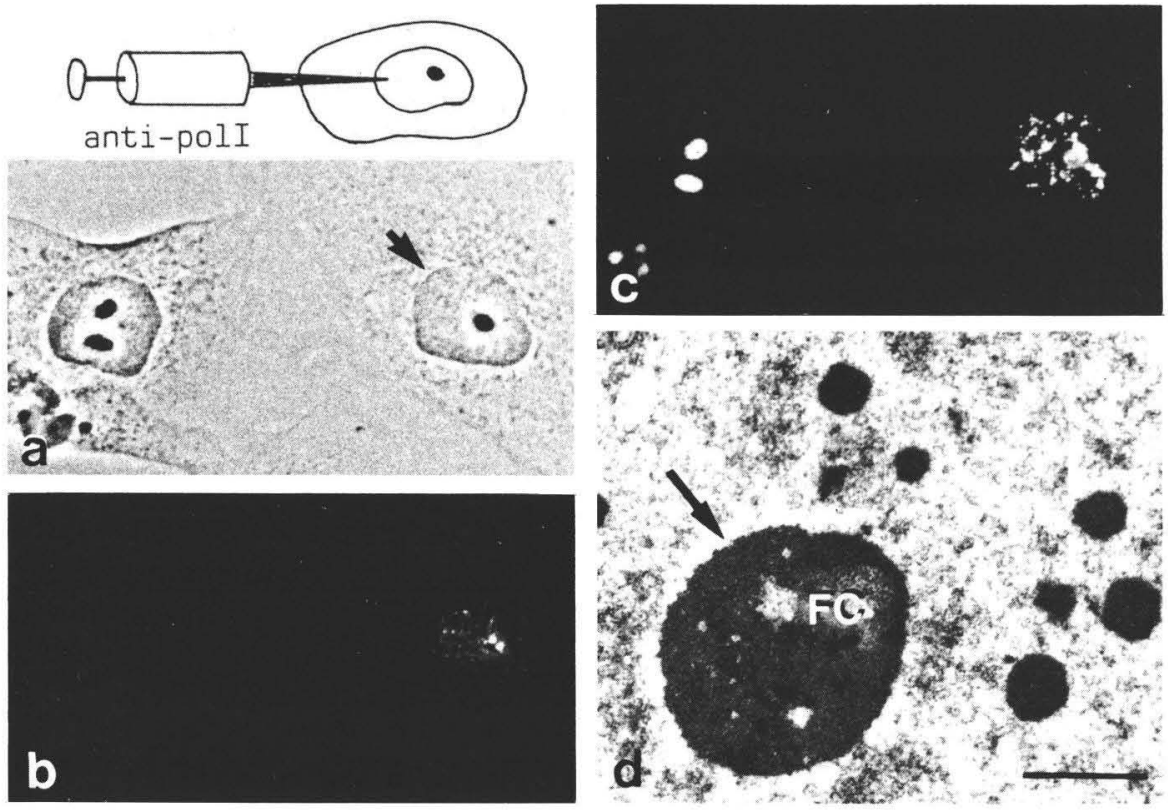

Fig. 5. Effect of antibodies to RNA polymerase I on nucleolar organization $4 \mathrm{~h}$ after microinjection into the nucleus of a cul-

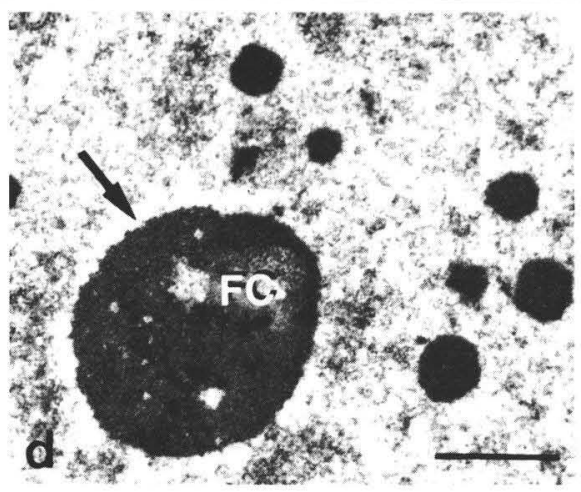
tured $\mathrm{PtK}_{2}$ cell (arrow in a) as seen by phase contrast (a) and double-label immunofluorescence microscopy $(b, c) .{ }^{(23)}$ The injected antibodies are concentrated in the nucleolus (b). Antibodies to fibrillarin stain numerous nucleoplasmic entities in the injected cell but not in adjacent control cells (c). Electron micrograph of the nucleus of an injected cell showing the residual nucleolus (arrow in d) which essentially consists of the granular component with fibrillar center (FC). The nucleoplasm is filled with numerous spherical aggregates with a dense fibrillar texture (d). Bar indicates $1 \mu \mathrm{m}(\mathrm{d})$.
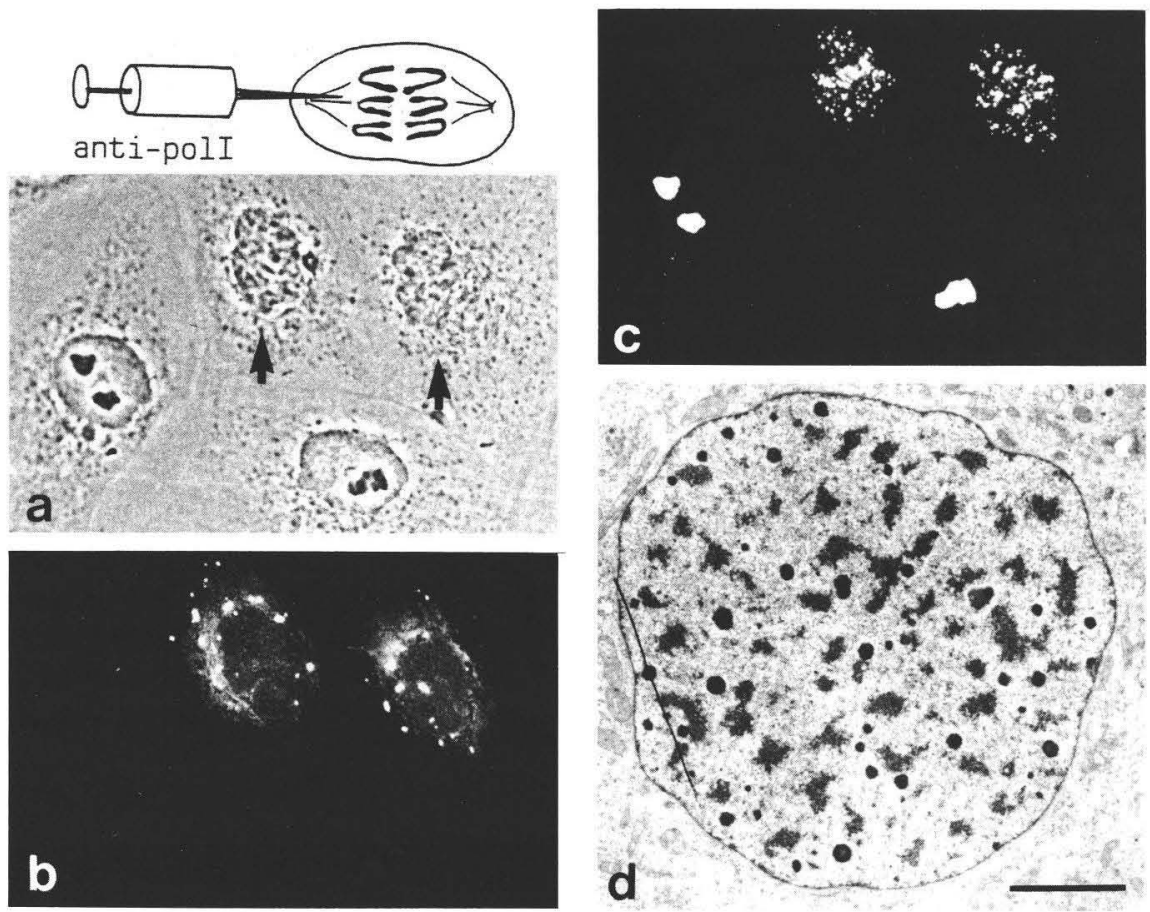

Fig. 6. Effect of antibodies to RNA polymerase I on postmitotic nuclear reformation. ${ }^{(28)} \mathrm{A} \mathrm{PtK}_{2}$ cell was injected at metaphase and the resulting daughter cells analyzed $3 \mathrm{~h}$ later. Daughter cells with reformed nuclei but lacking nucleoli are shown in phase contrast (arrows in a). The injected antibodies are largely excluded from the daughter nuclei (b). Double-label immunofluorescence microscopy with antibodies to fibrillarin reveals the presence of numerous prenucleolar bodies in the injected but not in adjacent control cells (c). Electron microscopy confirms the presence of prenucleolar bodies scattered throughout the nuclei of injected cells (d). Bar indicates $2 \mu \mathrm{m}$ (d).

electron microscopy (Fig.7). The results suggest that the nascent transcript fibrils rather than the chromatin itself mediate the interactions required for nucleologenesis and nucleolar stability. Furthermore, since the free ends of the transcript fibrils are preferentially decorated by the antibodies to fibrillarin (Fig. 7), we propose that the $5^{\prime}$-regions of the growing pre-rRNA molecules are specifically involved in establishing a structural link between the rRNA genes and the surrounding DFC.

\section{An Outline of Nucleolus Organization}

To date most models describing the molecular architec- ture of nucleoli tend to ignore the dimensions of the rRNA transcription units as compared to the size of the nucleolar body (see Fig. 2). Furthermore, the inventory of nucleolar proteins is still growing and the function of even abundant nucleolar proteins such as NO38/B23, a member of the nucleoplasmin family ${ }^{(29)}$, nucleolin/C23 $3^{(32,33)}$, and skeletal structural elements ${ }^{(34,35)}$ is unknown.

In contrast to previous models in which transcribing rRNA genes are assumed to loop out from the fibrillar centers into the surrounding $\mathrm{DFC},{ }^{(1,2,4,10)}$ our data point to the fibrillar centers as the exclusive sites of 


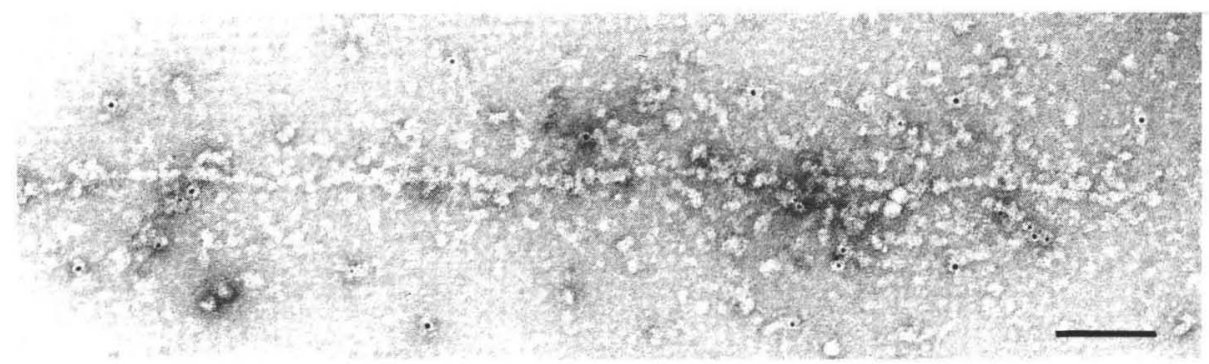

Fig. 7. Binding of fibrillarin antibodies to the free ends of nascent ribosomal transcript fibrils as shown by immunogold electron microscopy. Spread preparations of nucleolar chromatin were incubated with monoclonal antibodies to fibrillarin ${ }^{(24)}$ followed by secondary antibodies coupled to $5 \mathrm{~nm}$ gold particles and negative staining with uranyl acetate. Shown here is the terminal region of a ribosomal transcription unit. The chromatin axis with the densely packed RNA polymerases runs horizontally. Bar indicates $1.5 \mu \mathrm{m}$.

rDNA transcription. The boundary region between fibrillar centers and the surrounding DFC seems to play a key role in establishing and maintaining the structural integrity of the nucleolus. We propose that the nascent transcripts are enriched at the periphery of a fibrillar center where their free ends are sufficiently exposed to serve as nucleation sites for the assembly of the DFClayer. The intimate association of fibrillar centers with the DFC might provide a structural framework which links both transcriptional and posttranscriptional events and keeps transcription products in a specific topological order required for the subsequent cascade of maturation and processing steps.

\section{Perspectives}

It is tempting to speculate that the nucleolus exemplifies a more general principle of how the nucleus is ordered and subdivided into distinct functional territories. Thus it is conceivable that in analogy with the nucleolus the activity of any gene occurs within a structured framework, where transcription as well as processing and packaging of the transcripts with RNAbinding proteins takes place, followed by directional transport to the nuclear pore complexes. ${ }^{(36)}$

The forces that organize and maintain the complex nucleolar structure are as yet largely unknown. They might involve several structural proteins which could provide transient anchorage sites for preribosomal particles. $^{(34,35)}$ Specific signal sequences which could target certain proteins to the nucleolus or subnucleolar structures have recently been reported and may also play a role in structural and functional aspects of the nucleolus. ${ }^{(37)}$ Nevertheless, primary determinants of nucleolus development and maintenance appear to be the growing transcripts, be it the pre-rRNA molecules themselves or specific proteins bound to their $5^{\prime}$ termini. Since it has recently been shown that a single rDNA repeat is sufficient to organize a nucleolus ${ }^{(38)}$, identification of those rDNA sequences necessary for generating nucleolar structures is now within experimental reach.

\section{Acknowledgements}

We thank Hilde Merkert for expert technical assistance and K. Rose (University of Texas Medical School, Houston) for suggesting improvements to the manuscript. This work received financial support from the Deutsche Forschungsgemeinschaft (SFB 165).

\section{Note Added in Proof}

A recent study provided evidence for binding of U3 RNA to sequences close to the 5 '-end of the pre-rRNAs of human cells (Maser, R. L. \& Calvet, J. P. (1989). U3 small nuclear RNA can be psoralen-cross-linked in vivo to the $5^{\prime}$-external transcribed spacer of pre-ribosomal RNA. (Proc. Natl. Acad. Sci. USA 86, 6523-6527). Since the U3 ribonucleoprotein particle contains fibrillarin, these data are in full agreement with our immunolocalization results.

\section{References}

1 Hadjolov, A. A. (1985). The nucleolus and ribosome biogenesis. pp. 1-268 Springer Verlag, Wien, New York.

2 Sommerville, J. (1986). Nucleolar structure and ribosome biogenesis. Trends Biochem. Sci. 11, 438-442.

3 Howell, W. M. (1982). Selective staining of nucleolar organizer regions (NORs). In The Cell Nucleus, vol. 11 (eds. H. Busch \& L. Rothblum), pp. 90-142. Academic Press, New York.

4 Goessens, G. (1984). Nucleolar structure. Int. Rev. Cytol. 87, 107-158.

5 Jordan, E. G. \& McGovern J. H. (1981). The quantitative relationship of the fibrillar centers and other nucleolar components to changes in growth conditions, serum deprivation and low doses of actinomycin D in cultured diploid human fibroblasts (strain MRC-5). J. Cell Sci. 52, 373-389.

6 Miller, O. L. (1981). The nucleolus, chromosomes, and visualization of gene activity. J. Cell Biol. 91, 15s-27s.

7 Scheer, U. \& Zentgraf, H. (1982). Morphology of nucleolar chromatin in electron microscopic spread preparations. In The Cell Nucleus, vol. 11 (eds. H. Busch \& L. Rothblum), pp. 143-176. Academic Press, New York.

8 Rose, K. M., Stetler, D. A. \& JAcob, S. T. (1983). RNA polymerases from higher eukaryotes. In Enzymes of Nucleic Acid Synthesis and Modification (ed. S.T. Jacob), pp. 43-74. CRC Press, Boca Raton.

9 Grummi, I. (1989). Mammalian ribosomal gene organization. In Nucleic Acids and Molecular Biology, vol. 3 (eds. F. Eckstein \& D.M.J. Lilley), pp. 148-163. Springer Verlag, Berlin, Heidelberg.

10 Jordan, G. (1987). At the heart of the nucleolus. Nature 329, 489-490. 11 arroua, M. L., Hartung, M., Devictor, M., Berge-Lefranc, J. L. \& STAHL, A. (1982). Localization of ribosomal genes by in situ hybridization in the fibrillar center of the nucleolus in the human spermatocyte. Biol. Cell 44, $337-340$

12 Thiry, M. \& Thiry-Blaise, L. (1989). In situ hybridization at the electron microscope level: an improved method for precise localization of ribosomal DNA and RNA. Eur. J. Cell Biol. 50, 235-243. 
13 Scheer, U., Messner, K., Hazan, R., Raska, I., Hansmann, P., Falk, H., SPIESS, E. \& FrANKE, W. W. (1987). High sensitivity immunolocalization of double- and single-stranded DNA by a monoclonal antibody. Eur. J. Cell Biol. 43, 358-371.

14 Thiry, M., Scheer, U. \& Goessens, G. (1988). Localization of DNA within Ehrlich tumour cell nucleoli by immunoelectron microscopy. Biol. Cell 63, $27-34$.

15 ScheER, U. \& Rose, K. M. (1984). Localization of RNA polymerase I in interphase cells and mitotic chromosomes by light and electron microscopic immunocytochemistry. Proc. Natl. Acad. Sci. USA 81, 1431-1435.

16 Reimer, G., Raska, I., Tan, E. M. \& Scheer, U. (1987). Human autoantibodies: probes for nucleolus structure and function. Virchows Arch B 54, 131-143.

17 Raska, I., Reimer, G., Jarnik, M., Kostrouch, Z. \& Raska, K. (1989). Does the synthesis of ribosomal RNA take place within nucleolar fibrillar centers or dense fibrillar components? Biol. Cell 65, 79-82.

18 Rose, K. M., Szopa, J., Han, F. S., Cheng, Y. C., Richter, A. \& Scheer, U. (1988). Association of DNA topoisomerase I and RNA polymerase I: a possible role for topoisomerase I in ribosomal gene transcription. Chromosoma 96, 411-416

19 Steitz, J. A., Berg, C., Hendrick, J. P., La Branche-Chabot, H., Metspalu, A., Rinke, J. \& Yario, T. (1988). A 5S rRNA/L5 complex is a precursor to ribosome assembly in mammalian cells. J. Cell Biol. 106, 545-556. 20 REDDY, R. \& Busch, H. (1988). Small nuclear RNAs: RNA sequences, structure, and modifications. In Structure and Function of Major and Minor Small Nuclear Ribonucleoprotein Particles (ed. M.L. Birnstiel), pp. 1-37. Springer Verlag, Berlin.

21 Scheer, U., Hügle, B., Hazan, R. \& Rose, K. M. (1984). Drug-induced dispersal of transcribed rRNA genes and transcriptional products: immunolocalization and silver staining of different nucleolar components in rat cells treated with 5,6-dichloro- $\beta$-D-ribofuranosylbenzimidazole. J. Cell Biol. 99, 672-679.

22 Schlegel, R. A., Miller, L. S. \& Rose, K. M. (1985). Reduction in RNA synthesis following red cell-mediated microinjection of antibodies to RNA polymerase I. Cell Biol. Int. Rep. 9, 341-350.

23 Benavente, R., Reimer, G., Rose, K. M., Hügle-Dörr, B. \& Scheer, U. (1988). Nucleolar changes after microinjection of antibodies to RNA polymerase I into the nucleus of mammalian cells. Chromosoma 97, 115-123. 24 Reimer, G., Pollard, K. M., Pennig, C. A., Ochs, R. L., Lischwe, M. A., Busch, H. \& TAN, E. M. (1987). Monoclonal autoantibody from NZB/NZW F1 mouse and some human scleroderma sera target a $M_{r} 34,000$ nucleolar protein of the U3-ribonucleoprotein particle. Arthritis Rheum. 30 $793-800$

25 Ochs, R. L., Lischwe, M., Sронn, W. H. \& Busch, H. (1985). Fibrillarin a new protein of the nucleolus identified by autoimmune sera. Biol. Cell $\mathbf{5 4}$ $123-134$

26 De la Torre, C. \& Gimenez-Martin, G. (1982). The nucleolar cycle. In The Nucleolus (eds. E.G. Jordan \& C.A. Cullis), pp. 153-177. Cambridge University Press, Cambridge.
27 Jimenez-Garcia, L. F., Rothblum, L. I., Busch, H. \& Ochs, R. L. (1989). Nucleologenesis: use of non-isotopic in situ hybridization and immunocytochemistry to compare the localization of rDNA and nucleolar proteins during mitosis. Biol. Cell 65, 239-246.

28 Benavente, R., Rose, K. M., Reimer, G., Hügle-Dörr, B. \& Scheer, U. (1987). Inhibition of nucleolar reformation after microinjection of antibodies to RNA polymerase I into mitotic cells. J. Cell Biol. 105, 1483-1491.

29 Schmidt-Zachmann, M. S., Hügle-Dörr, B. \& Franke, W. W. (1987). A constitutive nucleolar protein identified as a member of the nucleoplasmin family. $E M B O$ J. 6, 1881-1890.

30 Geraud, G., Laquerriere, F., Masson, C., Arnould, J., Labidi, B. \& HeRnANDEZ-Verdun, D. (1989). Three-dimensional organization of micronuclei induced by colchicine in $\mathrm{PtK}_{1}$ cells. Exp. Cell Res. 181, 27-39.

31 Benavente, R., Schmidt-Zachmann, M. S., Hügle-Dörr, B., Reimer, G., Rose, K. M. \& SCHEer, U. (1988). Identification and definition of nucleolusrelated fibrillar bodies in micronucleated cells. Exp. Cell Res. 178, 518-523.

32 Lapeyre, B., Bourbon, H. \& Amalric, F. (1987). Nucleolin, the major nucleolar protein of growing eukaryotic cells: an unusual protein structure revealed by the nucleotide sequence. Proc. Natl. Acad. Sci. USA 84 , 1472-1476.

33 Caizergues-Ferrer, M., Mariottini, P., Curie, C., Lapeyre, B., Gas, N. Amalric, F. \& Amaldi, F. (1989). Nucleolin fron Xenopus laevis: cDNA cloning and expression during development. Genes Dev. 3, 324-333.

34 Franke, W. W., Kleinschmidt, J. A., Spring, H., Krohne, G., Grund, C., Trendelenburg, M. F., Stoehr, M. \& Scheer, U. (1981). A nucleolar skeleton of protein filaments demonstrated in amplified nucleoli of Xenopus laevis. J. Cell Biol. 90, 289-299.

35 Benavente, R., Krohne, G., Schmidt-Zachmann, M. S., Hügle, B. \& Franke, W. W. (1984). Karyoskeletal proteins and the organization of the amphibian oocyte nucleus. J. Cell Sci. (suppl.) 1, 161-186.

36 Lawrence, J. B., Singer, R. H. \& Marselle, L. M. (1989). Highly localized tracks of specific transcripts within interphase nuclei visualized by in situ hybridization. Cell 57, 493-502.

37 Siomi, H., Shida, H., Nam, S. H., Nosaka, T., Maki, M. \& HatanaKa, M. (1988). Sequence requirements for nucleolar localization of human T cell leukemia virus type I pX protein, which regulates viral RNA processing. Cell 55, 197-209.

38 Karpen, G. H., Schaefer, J. E. \& Laird, C. D. (1988). A Drosophila rRNA gene located in euchromatin is active in transcription and nucleolus formation. Genes Dev. 2, 1745-1763.

Ulrich Scheer and Ricardo Benavente are at the Institute of Zoology I, University of Würzburg, Röntgenring 10, D-8700 Würzburg, Federal Republic of Germany 


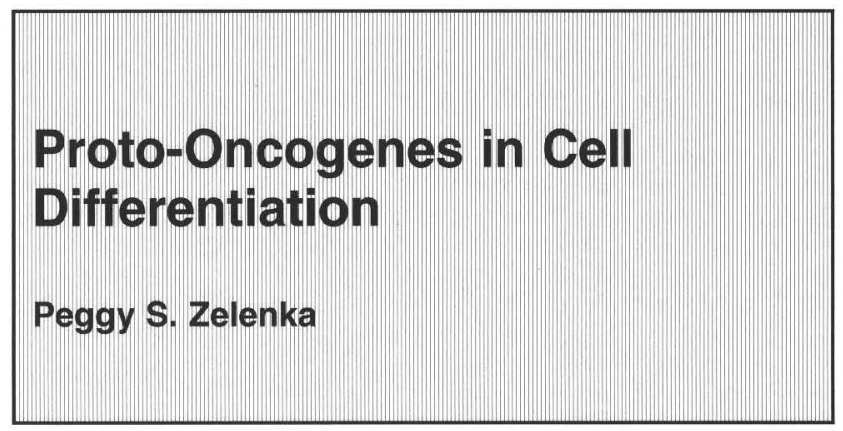

\section{Summary}

Proto-oncogene products may be multi-functional proteins with various roles in cell differentiation as well as cell proliferation. The molecular biology of the gene products of three well characterized proto-oncogenes ( $c$ fos, $c-m y c$ and $c$-src) are described, and the roles of three other proto-oncogene products, involved in hormone and growth factor reception, are reviewed.

\section{Introduction}

Proto-oncogenes are the normal cellular counterparts of the transforming oncogenes carried by retroviruses. Since it is known that viral oncogenes disrupt the control of cell proliferation and differentiation, it is thought that proto-oncogenes may play key roles in the normal regulation of these processes. Experiments designed to determine what these roles might be have identified biochemical activities for many proto-oncogene products, and are beginning to pinpoint the specific cellular pathways these proteins regulate. Proto-oncogene products have been implicated in almost every aspect of growth control, from the binding of growth factors to cell surface receptors, to signal transduction and the regulation of transcription. In many cases, elevated levels of proto-oncogene expression are associated with rapid cell proliferation.
This is not surprising, since expression of viral oncogenes leads to cell transformation. However, there are also circumstances in which proto-oncogene expression is elevated in non-dividing or differentiating cells, suggesting that certain proto-oncogene products may have specific functions during cell differentiation. This review will examine these cases, drawing examples from in situ studies of whole embryos, from numerous cell lines which can be induced to differentiate in vitro (Table 1), and from in vitro studies of normal embryonic tissues, including the embryonic chicken lens studied in my laboratory.

\section{c-fos}

The $c$-fos proto-oncogene is the normal homolog of the transforming gene carried by a murine sarcoma virus. ${ }^{(1,2)}$ The $c$-fos protein interacts with the protein product of another proto-oncogene, $c$-jun, to form a heterodimer able to recognize and bind to a specific sequence of nucleotides in the DNA. ${ }^{(3)}$ This sequence, TGAGTCA (also referred to as the tetradecanoylphorbol acetate responsive element, or TRE) is found in the promoter region of a family of genes. While only a few members of this family have been identified, many of these genes are expressed in transformed, rapidly growing cells: examples include collagen $\alpha_{1}$ (III), collagenase, transin (also called stromeolysin, a metalloproteinase which degrades extracellular matrix), and the $c$-fos product itself. ${ }^{(4,5)}$ The regulation of such genes by $c$-fos is consistent with observations that $c$-fos expression is required for cell proliferation. Nevertheless, another gene which is regulated by $c$-fos, the gene for the lipid-binding protein, adipocyte $\mathrm{P} 2$, is expressed only in differentiated adipocytes. ${ }^{(6)}$ In addition, $c$-fos expression is linked to differentiation of certain other cell types, although the specific genes regulated have not been identified. For example, c-fos expression increases during the differentiation of HL60 and U-937 monomyelocytes to form macrophages, and during differentiation of PC12 cells to form neurons ${ }^{(1)}$.

Table 1. Cell lines commonly used to study cell differentiation

\begin{tabular}{llll}
\hline Cell Line & Cell Type & Differentiates into: & Agent \\
\hline PC12 & murine pheochromocytoma & neuronal cell & NGF \\
F9 & murine teratocarcinoma & parietal endoderm & cAMP+RA \\
MEL & murine erythroleukemia & erythrocyte & DMSO \\
& & & HX \\
3T3-F442A & murine preadipocyte & adipocyte & HMBA \\
WEHI-231 & murine early B lymphocyte & B lymphocyte & LPS \\
WEHI-3B & murine myelomonocyte & macrophage & GM-CSF \\
HL60 & human myelomonocyte & macrophage & TPA \\
& & granulocyte & VitD 3 \\
& & DMSO \\
U-937 & human myelomonocyte & macrophage & RA
\end{tabular}

Abbreviations used: NGF, nerve growth factor; cAMP, 2'-5' cyclic adenosine monophosphate; RA, retinoic acid; DMSO,

dimethylsulfoxide; HX, hypoxanthine; HMBA, hexamethylenebisacetamide; FCS, fetal calf serum; INS, insulin; LPS, bacterial

lipopolysaccharide; GM-CSF, granulocyte/macrophage colony stimulating factor; TPA, tetradecanoylphorbol acetate; Vit $\mathrm{D}_{3}$, vitamin $\mathrm{D}_{3}$. 